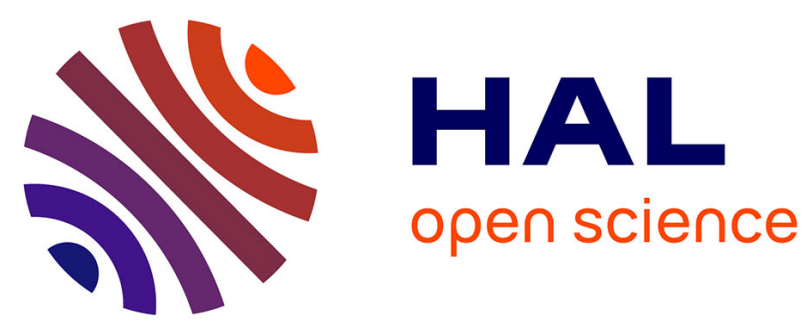

\title{
Large Sequence-Defined Supramolecules Obtained by the DNA-Guided Assembly of Biohybrid Poly(phosphodiester)s
}

Tathagata Mondal, Maria Nerantzaki, Kevin Flesch, Capucine Loth, Mounir Maaloum, Yidan Cong, Sergei S Sheiko, Jean-François Lutz

\section{To cite this version:}

Tathagata Mondal, Maria Nerantzaki, Kevin Flesch, Capucine Loth, Mounir Maaloum, et al.. Large Sequence-Defined Supramolecules Obtained by the DNA-Guided Assembly of Biohybrid Poly(phosphodiester)s. Macromolecules, 2021, 54 (7), pp.3423-3429. 10.1021/acs.macromol.0c02581 . hal-03454732

\section{HAL Id: hal-03454732 https://hal.science/hal-03454732}

Submitted on 29 Nov 2021

HAL is a multi-disciplinary open access archive for the deposit and dissemination of scientific research documents, whether they are published or not. The documents may come from teaching and research institutions in France or abroad, or from public or private research centers.
L'archive ouverte pluridisciplinaire HAL, est destinée au dépôt et à la diffusion de documents scientifiques de niveau recherche, publiés ou non, émanant des établissements d'enseignement et de recherche français ou étrangers, des laboratoires publics ou privés. 


\title{
Large sequence-defined supramolecules obtained
}

\author{
by DNA-guided assembly of bio-hybrid \\ poly(phosphodiester)s
}

Tathagata Mondal, ${ }^{[a]}$ Maria Nerantzaki, ${ }^{[a]}$ Kevin Flesch, ${ }^{[a]}$ Capucine Loth, ${ }^{[a]}$ Mounir Maaloum, ${ }^{[a]}$ Yidan Cong, ${ }^{[b]}$ Sergei S. Sheiko ${ }^{[b]}$ and Jean-François Lutz*[a]

AUTHOR ADDRESS. ${ }^{1}$ Université de Strasbourg, CNRS, Institut Charles Sadron UPR22, 23 rue du Loess, 67034 Strasbourg Cedex 2, France. ${ }^{2}$ Department of Chemistry, University of North Carolina at Chapel Hill, Chapel Hill, North Carolina 27599-3290, USA.

Published in Macromolecules, 54, 3423-3429 (2021)

https://pubs.acs.org/doi/10.1021/acs.macromol.0c02581 
ABSTRACT. The DNA-guided assembly of bio-hybrid sequence-defined poly(phosphodiester)s was investigated. These polymers contain long non-natural segments covalently connected to single-stranded DNA sequences. These bio-hybrid structures were synthesized by automated phosphoramidite chemistry using both nucleoside- and abiologicalphosphoramidite monomers. Using complementary DNA strands, the precursors were then assembled in aqueous buffer into linear of star-like superstructures. For instance, linear supramolecules containing 442 (352 non-natural monomers connected by three doublestranded DNA bridges of 15 base pairs) and 990 monomers (720 non-natural monomers connected by nine double-stranded DNA bridges of 15 base pairs) were prepared. A four-arm star structure containing 488 monomers (352 non-natural monomers connected by a 4-arm junction of 68 base pairs) was also achieved. The formed supramolecules were characterized by electrophoresis, UV spectroscopy and atomic force microscopy. All these techniques evidenced the formation of the expected supramolecules, even some defects were also evidenced. These results open up interesting avenues for the design of $2 \mathrm{D}$ and $3 \mathrm{D}$ constructs based on informational poly(phosphodiester)s. 


\section{INTRODUCTION.}

Since the early days of polymer science that started 100 years ago, ${ }^{1-2}$ polymer chemists have predominantly synthesized polydisperse macromolecules, in which polymer chains have nonuniform molecular structures. Synthetic polymers are obtained via two main mechanisms, namely step-growth and chain-growth polymerizations. ${ }^{3}$ These approaches are straightforward but obey statistical laws leading to polydispersity. Even advanced chain-growth methods such as living anionic polymerizations and controlled radical polymerizations lead to polydisperse samples. ${ }^{4-5}$ To achieve the chemical synthesis of uniform macromolecules, more precise, but demanding, multistep-growth protocols have to be employed. ${ }^{3}$ For example, solid-phase iterative chemistry, ${ }^{6}$ dendrimer synthesis, ${ }^{7}$ self-interrupted polymerization ${ }^{8}$ and iterative exponential growth ${ }^{9}$ are all methods that allow synthesis of uniform polymers. However, such multistep strategies are inherently limited by the yields of their repeated chemical steps. Thus, they are usually restricted to small-scale synthesis and to the preparation of oligomers; although a few examples of larger macromolecules have been reported. ${ }^{10-14}$ Overall, it is challenging to prepare a perfectly uniform linear polymer chain containing more than 100 monomer units by chemical synthesis. In comparison, nature can achieve ultra-long macromolecules with a perfectly uniform molecular structure. The human chromosome 1 is, for example, composed of two hybridized DNA chains, each of which containing a perfectly defined sequence of 248956422 monomers (i.e. more than 248 million). ${ }^{15}$ It is currently impossible to synthesize (and even to conceive) a synthetic macromolecule with similar features by man-made polymer chemistry. ${ }^{16-17}$ Here, we report a simple method to prepare large sequence-defined macromolecules. This approach combines a multistep-growth phosphoramidite approach ${ }^{18}$ with single-strand DNA hybridization. ${ }^{19}$ Using this strategy, supramolecules with different chain-lengths, topologies and sequences were prepared. 


\section{RESULTS AND DISCUSSION.}

Design and synthesis of bio-hybrid polymers. Figure 1 shows the concept explored in this work. Since multistep growth approaches are limited in length by reaction yields, one possible solution to attain longer uniform macromolecules is to ligate preformed uniform precursors into a larger construct. Both covalent and non-covalent strategies may be considered for the ligation of preformed macromolecules. For instance, covalent approaches, such a native chemical ligation, have been already successfully developped for the total synthesis of large man-made proteins. ${ }^{20}$ However, the covalent ligation of macromolecular reagents is usually affected by a kinetic exclusion effect that strongly limits the reactivity of high-molecular weight precursors. ${ }^{21}$ An interesting alternative to stepwise covalent ligation would be the development of a supramolecular strategy. Over the last two decades, the sequence-specific hybridization of single-stranded DNA (ssDNA) segments has been evidenced to be a versatile strategy for materials self-assembly. ${ }^{19}$ This concept can be used not only to create large 2D and 3D DNA constructs ${ }^{22-24}$ but also to assemble non-biological matter such as nanoparticles, nanotubes and synthetic polymers. ${ }^{25}$ In the latter case, ssDNA-hybridization has been mostly used to ligate non-uniform segments into supramolecular block copolymers. ${ }^{26-28}$ In particular, remarkable progress in that area was achieved by Herrmann and coworkers for the synthesis of DNA (multi)block copolymers using selective hybridization ${ }^{29}$ but also other tools such as enzymatic ligation ${ }^{30}$ and the polymerase chain reaction. ${ }^{31-32}$ However, to date, the construction of DNA assemblies containing molecularly-uniform synthetic elements has only been investigated by Sleiman and coworkers. ${ }^{33-34}$ Overall, DNA self-assembly has not been fully exploited for the synthesis of non-natural polymer architectures, in particular for the preparation of sequence-defined constructs.

Automated phosphoramidite chemistry is a tool of choice for preparing uniform polymers containing synthetic segments attached to DNA sequences. Indeed, both biological and non- 
biological monomers can be used in this approach. ${ }^{18,35-36}$ Thus, using a DNA synthesizer, it is possible to synthesize bio-hybrid macromolecules containing a long non-natural segment connected to one or two ssDNA extremities (Figure 1). Figure 1a shows the biological and nonbiological monomer alphabets used in this work to construct these polymers. The ssDNA segments were synthesized using standard commercial nucleoside phosphoramidites A, T, G and C. To prepare the abiotic sequence-defined poly(phosphodiester)s (PPDE) segments, ${ }^{37}$ two phosphoramidite monomers containing either propyl or dimethyl-propyl motifs were employed. These building blocks have been used in previous works for the synthesis of digital sequences $^{12,38}$ and are therefore convenient models for this first proof-of-concept. Abiotic digital poly(phosphodiester)s can be decoded using different sequencing techniques ${ }^{39}$ such as tandem mass spectrometry ${ }^{40}$ and nanopore sequencing. ${ }^{41}$ Figure $1 \mathrm{~b}$ shows the general molecular structure of the bio-hybrid polymers synthesized herein. Three different types of macromolecules were prepared: triblocks 5'-DNA- $b$-PPDE- $b$-DNA-3' and diblocks 5'-DNA$b$-PPDE-3' and 5'-PPDE- $b$-DNA-3'. ${ }^{37}$ In the DNA-guided assembly process schematized in Figure 1c, the triblocks are inner-segments that can be connected on both sides, whereas the diblocks are terminal outer-segments. For linear constructs, the chain-length of the non-natural PPDE and ssDNA segments was set at 88 and 15 residues, respectively. The motivation behind this choice is that although the bio-hybrid macromolecules contain mainly non-natural information, the oligonucleotide sequences shall remain of sufficient size to achieve sequencespecific hybridization. For non-linear constructs, 34-mer DNA segments were utilized to achieve multistranded 4-arm junctions. ${ }^{42-43}$ The defined monomer sequences of the non-natural PPDE segments were shaped following previously-reported encoding rules. ${ }^{40,44}$ The ssDNA sequences were selected from the literature based on two main criteria: (i) sequence-selective duplex formation of complementary strands and (ii) formation of duplexes with noticeablydifferent melting temperatures $T_{\mathrm{m}}$ in order to characterize the DNA-guided assembly by UV 
spectroscopy. ${ }^{43,45-46}$ Table S1 shows the monomer sequence of the polymers P1-P18 that were studied in this work. All these polymers were synthesized by automated phosphoramidite chemistry, purified using a reverse-phase column and characterized by HPLC and SEC. ${ }^{12}$ In all cases, HPLC evidenced formation of monodisperse bio-hybrid macromolecules. Due to the high chain-length and high fraction of nucleotides of these polymers, it was not possible to detect most of them by mass spectrometry. However, when detected by electrospray mass spectrometry, spectrum revealed uniform single species (Figure S1), as evidenced by HPLC results. These bio-hybrid macromolecules were then used for programmed DNA assembly, as described below.

a.
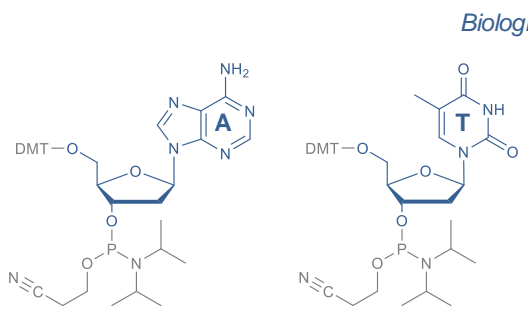

Biological alphabet
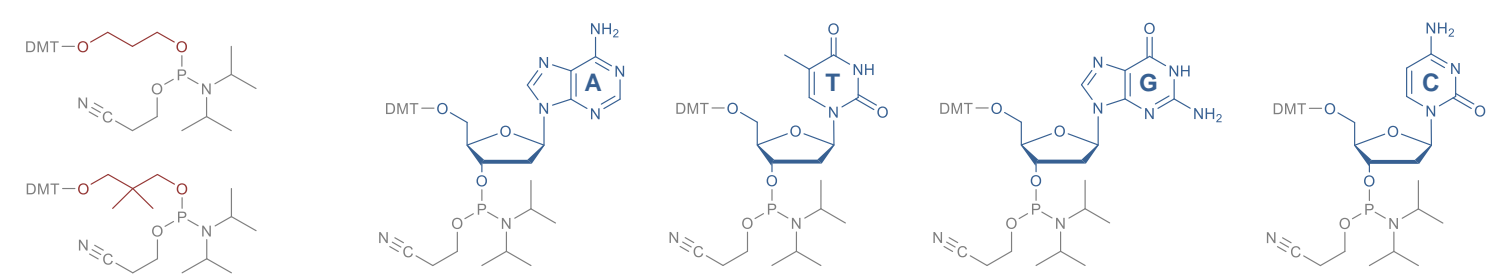

b.
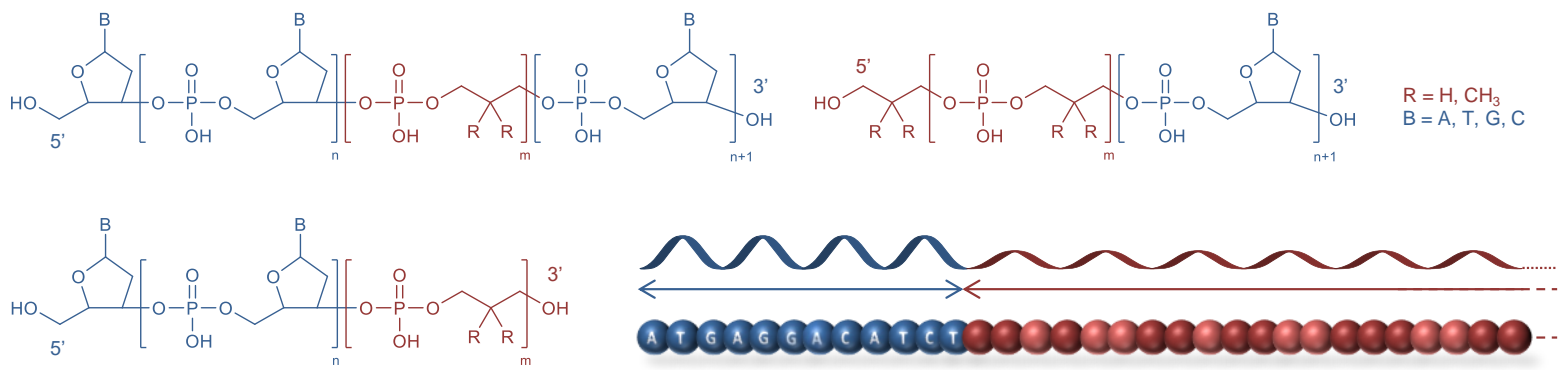

DNA single-strand

non-natural sequence-defined segmen

c.

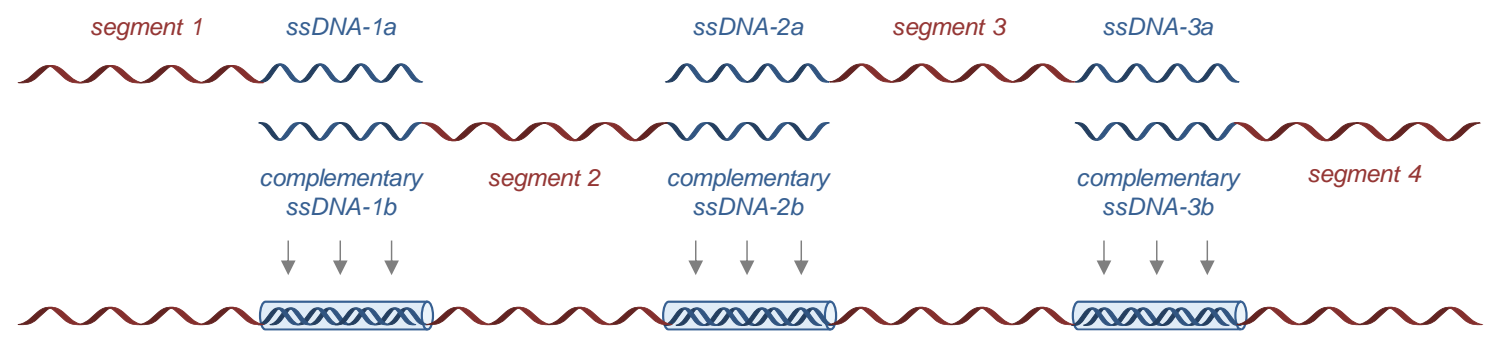

Figure 1. (a) Molecular structure of the phosphoramidite monomers used in this work. (b) Molecular structure of the different types of bio-hybrid poly(phosphodiester)s used for DNAguided self-assembly. (c) General concept investigated herein for the synthesis of large sequence-defined supramolecules. 
Preparation of linear supramolecules. DNA assembly was first explored for the preparation of linear supramolecules. Polymers P1-P4 were conceived for constructing a sequence-defined supramolecule S1 containing 442 monomers; i.e. four blocks of 88 nonnatural monomers connected by three double-stranded DNA sections of 15 base pairs (bp) each (Figure 2a). Assembly was performed by mixing four individual solutions $(5 \mu$-molar concentration) of the starting polymers in phosphate buffer saline (PBS), following by heating at $80^{\circ} \mathrm{C}$ and slow cooling. The resulting superstructure $\mathbf{S 1}$ was characterized by UV spectroscopy, electrophoresis and atomic force microscopy (AFM). Figure 2c shows the UV melting curve recorded for $\mathbf{S} \mathbf{1}$ and its first derivative. As mentioned in the previous section, the DNA sequences were selected in order to obtain distinguishable $T_{\mathrm{m}}$. In the case of $\mathbf{S 1}$, the three 15-bp double-stranded DNA sections were selected from the literature ${ }^{45}$ and, in the studied experimental conditions (PBS, $\mathrm{pH} \sim 7.4,100 \mathrm{mM} \mathrm{NaCl}$ ), have theoretical $T_{\mathrm{m}}$ of 40,51 and $59^{\circ} \mathrm{C}$, according to the online prediction software OligoCalc. The first derivative of the experimental UV melting curve evidenced three distinct melting temperatures at 39, 55 and $65^{\circ} \mathrm{C}$, which are consistent with the reported values. ${ }^{45}$ It shall be noted that software-predicted $T_{\mathrm{m}}$ values are only indicative and do not take into account the influence of polymer conjugation on $T_{\mathrm{m}}$. The DNA-guided self-assembly was also confirmed by electrophoresis, which evidenced the formation of a superstructure of much higher molecular weight than the individual precursors P1-P4 (Figure S2). S1 was also studied by AFM, which is a tool of choice for the imaging of discrete supramolecules. ${ }^{47-48}$ The assembly solutions were diluted in deionized water and deposited on a mica substrate. After washing off salt crystals that prevent imaging, ${ }^{49}$ individual superstructures were observed (Figure $2 \mathrm{~d}$ ). Some of these structures have a length of about $250 \mathrm{~nm}$, which is consistent with the calculated $\mathbf{S 1}$ contour length of an extended supramolecule. Yet, other appears folded and globular. The observed conformations might be due to the flexibility of the non-natural PPDE segments, which have a smaller 
persistence length than double stranded DNA. In addition, the observation of smaller granular shapes confirms the presence of defects, which can be partially-formed superstructures. S1 was further studied by AFM in solution (Figure 2e). ${ }^{50}$ This study indicated that the elongated structures contain long flexible domains ( $1 \mathrm{~nm}$ thick) and three shorter and thicker regions (2.4 $\mathrm{nm}$ thick), which is in good accordance with the thickness of double-stranded DNA and the expected morphology of S1.

a.

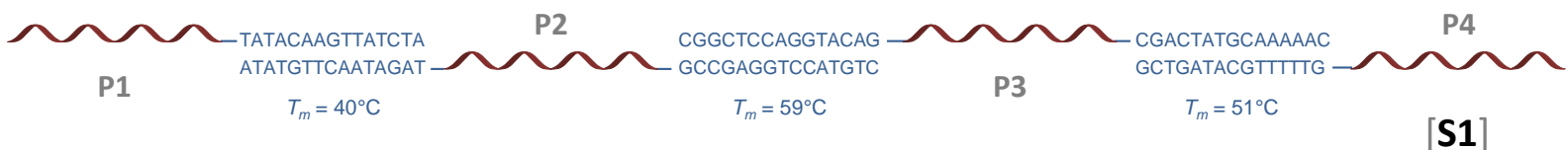

b.

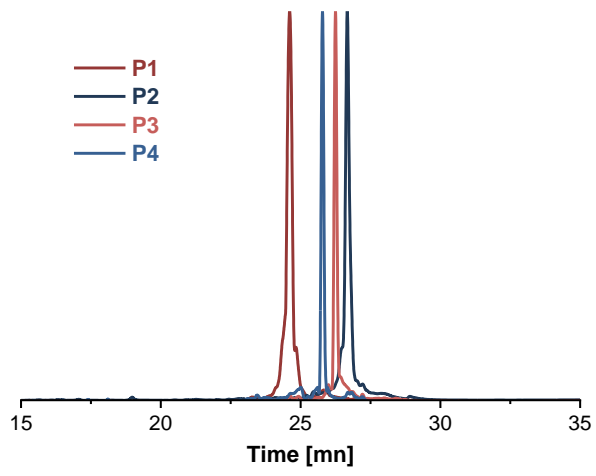

d.

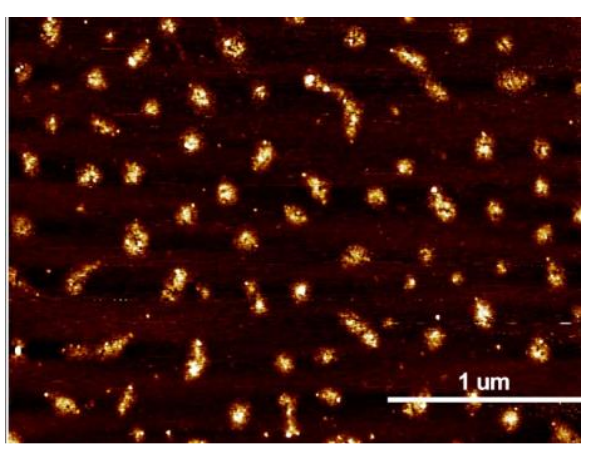

c.

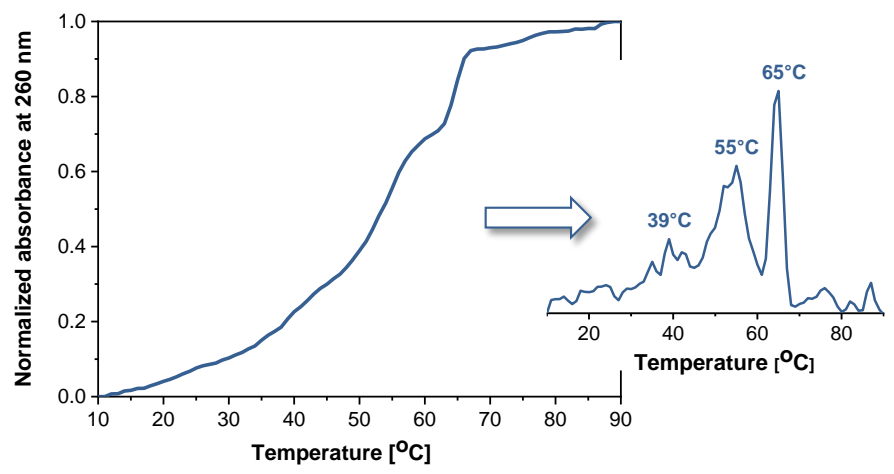

e.

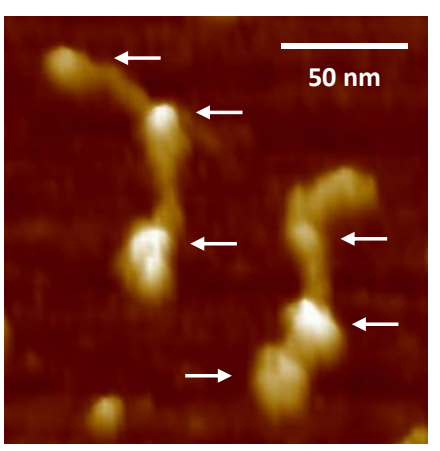

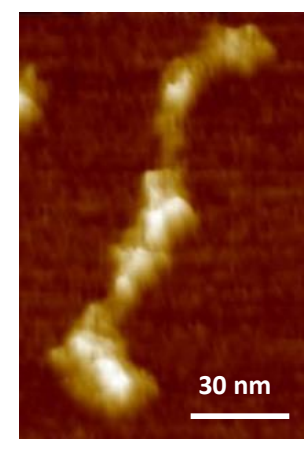

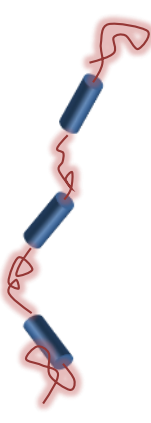

Figure 2. Linear supramolecule S1 obtained by DNA-guided assembly of polymers P1-P4. (a) Schematized representation of the hybridized superstructure. The displayed melting temperatures $\mathrm{Tm}$ are theoretical values calculated with the software OligoCalc. (b) Ionexchange HPLC traces recorded for the individual polymers P1-P4. (c) UV melting curves recorded for the assembled structure S1. The inset shows the first derivative of the melting curve. (d) Height AFM micrographs of S1 recorded on a dried substrate. (e) Height AFM micrographs of $\mathbf{S 1}$ recorded in aqueous solution. 
The concept was then explored for the fabrication of larger linear constructs based on precursors P5-P14 (Table S1, Figure S3). The expected superstructure S2 shall contain 990 monomers; i.e. ten blocks of 72 non-natural monomers connected by nine double-stranded DNA sections of $15 \mathrm{bp}$ each (Scheme S1). Since it is unlikely to observe nine distinct $T_{\mathrm{m}}$ in melting curves, three groups of three double-strands, which exhibit theoretical $T_{\mathrm{m}}$ around 40 , 55 and $65^{\circ} \mathrm{C}$ were used. ${ }^{46}$ Figures $\mathrm{S} 4$ and S5 show the UV spectroscopy and AFM characterization of the resulting superstructure S2, which was prepared in the same experimental conditions as S1. The first derivative of the UV melting curves clearly evidences three events with $T_{\mathrm{m}}$ of 36,56 and $70^{\circ} \mathrm{C}$. Dispersity was confirmed by AFM images (Figure S5), which evidence large clusters co-existing with smaller defects. Probably due to the flexibility of the PPDE chains, the formed superstructures do not appear as elongated objects but fold into aggregated clusters.

Preparation of non-linear supramolecules. The concept described in this communication is not restricted to linear constructs. DNA hybridization also potentially enables the preparation of a wide variety of non-linear architectures. ${ }^{19,25}$ As a proof-of-concept, the construction of a 4-arm star superstructure based on a Holliday junction was examined. The 4-arm junction utilized herein is based on four ssDNA 34-mer (Figure 3) and is a non-migrating model of the biological four-way junction with well-documented conformations, dynamics and denaturation. ${ }^{43}$, 51-52 The expected superstructure $\mathbf{S 3}$ shall contain 488 monomers (352 nonnatural monomers connected by a 4 -arm junction of 68 base pairs). In the present experimental conditions, the formed junction has a theoretical $T_{\mathrm{m}}$ of about $60^{\circ} \mathrm{C} .{ }^{40}$ As shown in Figure $3 \mathrm{~b}$, the PBS assembly of polymers P15-P18 leads to a superstructure $\mathbf{S 3}$ with an experimental $T_{\mathrm{m}}$ of $66^{\circ} \mathrm{C}$. The formation of $\mathbf{S 3}$ was also confirmed by electrophoresis (Figure S6). AFM studies also confirmed the star-like morphology and evidenced the presence 4-arm-stars with an arm- 
length of about $50 \mathrm{~nm}$ (Figure 3c), which roughly correspond to the expected extended length.

These superstructures have a tendency to aggregate and only a few supramolecules could be imaged individually.

a.

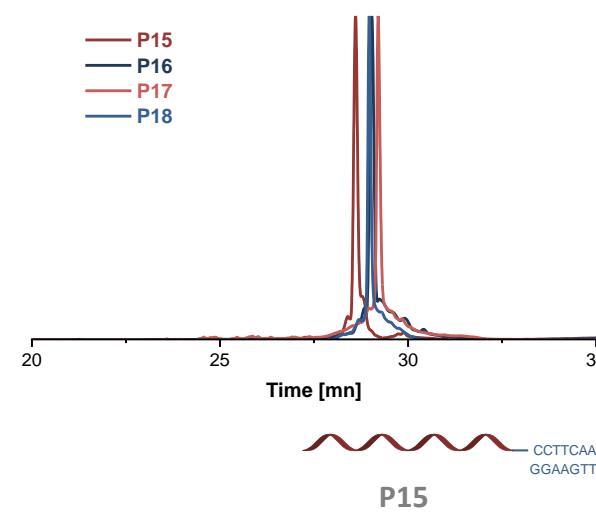

c.

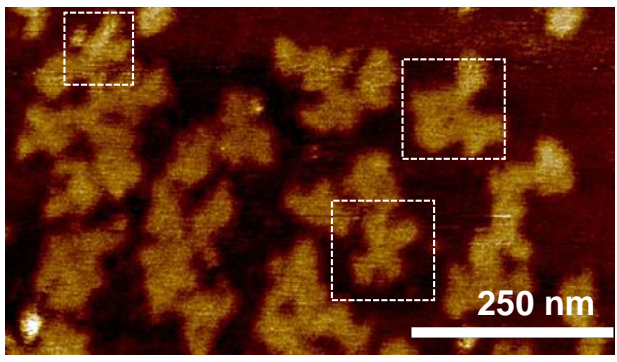

b.

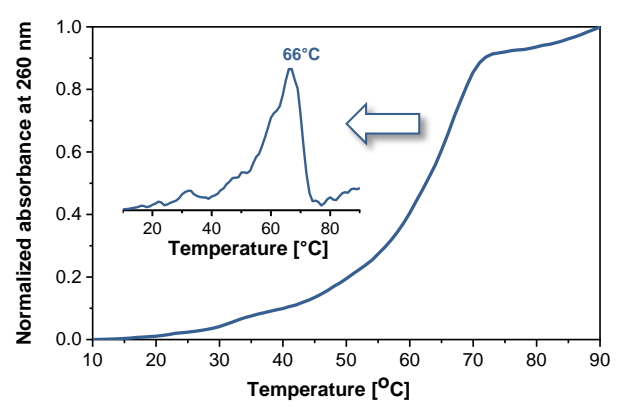

P17

$T_{m} \sim 60^{\circ} \mathrm{C}$

n

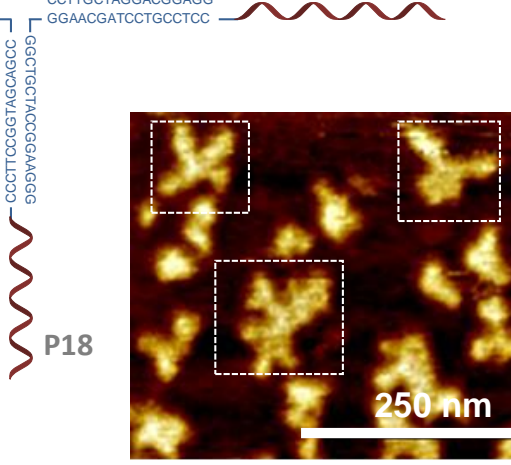

Figure 3. Star-shaped supramolecule $\mathbf{S 3}$ obtained by DNA-guided assembly of polymers P15P18. (a) Ion-exchange HPLC traces recorded for the individual polymers P15-P18. (b) UV melting curve recorded for the assembled structure S3. The inset shows the first derivative of the melting curve. (c) Height AFM micrographs of S3.

\section{CONCLUSION.}

In summary, these results indicate that DNA hybridization allows assembly of macromolecular building-blocks with precisely-controlled chain-length and monomer sequences. Due to the versatility of automated phosphoramidite chemistry, it is relatively easy to synthesize sequence-defined bio-hybrid DNA/ PPDE block copolymers and to assemble them into precise linear or non-linear constructs. Yet, the quality of the assembly seems to depend on the starting number of macromolecular precursors. Although well-controlled 
assembly was observed with four bio-hybrid components, a higher amount of defects was detected when ten components were used. Still, the method is valid and opens up interesting perspectives for the spatial organization of abiotic informational sequences, including digitallyencoded polymers that show promises in data storage applications. ${ }^{53}$ This strategy is indeed not restricted to the two non-biological monomers used herein and can be applied to a broad variety of other phosphoramidite monomers. ${ }^{35,54}$ Furthermore, the simple linear and star-like topologies examined in this work are only selected examples among a vast number of possibilities. $^{25}$ For example, precisely-organized $2 \mathrm{D}$ or $3 \mathrm{D}$ information networks can be foreseen with this approach.

\section{ASSOCIATED CONTENT}

Supporting Information. Full experimental part. This material is available free of charge via the Internet at http://pubs.acs.org.

\section{AUTHOR INFORMATION}

\section{Corresponding Author}

* Jean-François Lutz: jflutz@,unistra.fr

\section{Funding Sources}

J.-F.L. thanks the excellence network Chemistry of Complex Systems (LabEx CSC) and the CNRS for financial support. M.N. thanks the Bodossaki Foundation for postdoctoral research funding for the period 2018-2021.

\section{ACKNOWLEDGMENT}

J.-F.L. thanks the excellence network Chemistry of Complex Systems (LabEx CSC) and the CNRS for financial support. M.N. thanks the Bodossaki Foundation for postdoctoral research 
funding for the period 2018-2021. The MS results were kindly provided by Laurence Charles (Aix Marseille Université). The SEC results were obtained with the help of the polymer characterization service of the Institut Charles Sadron. The authors thank Mélanie Legros and Catherine Foussat (Institut Charles Sadron) for helpful discussions.

\section{REFERENCES}

1. Staudinger, H., Über Polymerisation. Ber. Dtsch. Chem. Ges. 1920, 53, 1073-1085.

2. $\quad$ Carothers, W. H., Polymerization. Chem. Rev. 1931, 8, 353-426.

3. Lutz, J.-F.; Lehn, J.-M.; Meijer, E. W.; Matyjaszewski, K., From precision polymers to complex materials and systems. Nat. Rev. Mater. 2016, $1,16024$.

4. Szwarc, M., 'Living' Polymers. Nature 1956, 178, 1168-1169.

5. Patten, T. E.; Xia, J.; Abernathy, T.; Matyjaszewski, K., Polymers with Very Low Polydispersities from Atom Transfer Radical Polymerization. Science 1996, 272, 866.

6. Lutz, J.-F.; Ouchi, M.; Liu, D. R.; Sawamoto, M., Sequence-Controlled Polymers. Science 2013, 341, 1238149.

7. Tomalia, D. A.; Fréchet, J. M. J., Discovery of dendrimers and dendritic polymers: A brief historical perspective. J. Polym. Sci., Part A: Polym. Chem. 2002, 40, 2719-2728.

8. Holerca, M. N.; Peterca, M.; Partridge, B. E.; Xiao, Q.; Lligadas, G.; Monteiro, M. J.; Percec, V., Monodisperse Macromolecules by Self-Interrupted Living Polymerization. J. Am. Chem. Soc. 2020, 142, 15265-15270.

9. Takizawa, K.; Tang, C.; Hawker, C. J., Molecularly Defined Caprolactone Oligomers and Polymers: Synthesis and Characterization. J. Am. Chem. Soc. 2008, 130, 17181726.

10. LeProust, E. M.; Peck, B. J.; Spirin, K.; McCuen, H. B.; Moore, B.; Namsaraev, E.; Caruthers, M. H., Synthesis of high-quality libraries of long (150mer) oligonucleotides by a novel depurination controlled process. Nucleic Acids Res. 2010, 38, 2522-2540.

11. Nguyen, T.-T.-T.; Baumgarten, M.; Rouhanipour, A.; Räder, H. J.; Lieberwirth, I.; Müllen, K., Extending the Limits of Precision Polymer Synthesis: Giant Polyphenylene Dendrimers in the Megadalton Mass Range Approaching Structural Perfection. J. Am. Chem. Soc. 2013, 135, 4183-4186.

12. Al Ouahabi, A.; Kotera, M.; Charles, L.; Lutz, J.-F., Synthesis of Monodisperse Sequence-Coded Polymers with Chain Lengths above DP100. ACS Macro Lett. 2015, 1077-1080. 
13. Lee, J. M.; Koo, M. B.; Lee, S. W.; Lee, H.; Kwon, J.; Shim, Y. H.; Kim, S. Y.; Kim, K. T., High-density information storage in an absolutely defined aperiodic sequence of monodisperse copolyester. Nat. Commun. 2020, 11, 56.

14. Hartrampf, N.; Saebi, A.; Poskus, M.; Gates, Z. P.; Callahan, A. J.; Cowfer, A. E.; Hanna, S.; Antilla, S.; Schissel, C. K.; Quartararo, A. J.; Ye, X.; Mijalis, A. J.; Simon, M. D.; Loas, A.; Liu, S.; Jessen, C.; Nielsen, T. E.; Pentelute, B. L., Synthesis of proteins by automated flow chemistry. Science 2020, 368, 980.

15. Genome Reference Consortium, https://www.ncbi.nlm.nih.gov/grc/human/data

16. Lutz, J.-F., Can Life Emerge from Synthetic Polymers? Isr. J. Chem. 2020, 60, 151159.

17. Lutz, J.-F., 100th Anniversary of Macromolecular Science Viewpoint: Toward Artificial Life-Supporting Macromolecules. ACS Macro Lett. 2020, 9, 185-189.

18. Caruthers, M. H., Gene synthesis machines: DNA chemistry and its uses. Science 1985, 230, 281-285.

19. Seeman, N. C., DNA in a material world. Nature 2003, 421, 427.

20. Kent, S. B. H., Total chemical synthesis of proteins. Chem. Soc. Rev. 2009, 38, 338351.

21. Morawetz, H., Reaction kinetics of polymeric reagents. J. Polym. Sci., Polym. Sym. 1985, 72, 9-15.

22. Rothemund, P. W. K., Folding DNA to create nanoscale shapes and patterns. Nature 2006, 440, 297.

23. Ong, L. L.; Hanikel, N.; Yaghi, O. K.; Grun, C.; Strauss, M. T.; Bron, P.; Lai-Kee-Him, J.; Schueder, F.; Wang, B.; Wang, P.; Kishi, J. Y.; Myhrvold, C.; Zhu, A.; Jungmann, R.; Bellot, G.; Ke, Y.; Yin, P., Programmable self-assembly of three-dimensional nanostructures from 10,000 unique components. Nature 2017, 552, 72.

24. Wagenbauer, K. F.; Sigl, C.; Dietz, H., Gigadalton-scale shape-programmable DNA assemblies. Nature 2017, 552, 78.

25. Aldaye, F. A.; Palmer, A. L.; Sleiman, H. F., Assembling Materials with DNA as the Guide. Science 2008, 321, 1795.

26. McLaughlin, C. K.; Hamblin, G. D.; Hänni, K. D.; Conway, J. W.; Nayak, M. K.; Carneiro, K. M. M.; Bazzi, H. S.; Sleiman, H. F., Three-Dimensional Organization of Block Copolymers on "DNA-Minimal" Scaffolds. J. Am. Chem. Soc. 2012, 134, 42804286.

27. Lu, X.; Watts, E.; Jia, F.; Tan, X.; Zhang, K., Polycondensation of Polymer Brushes via DNA Hybridization. J. Am. Chem. Soc. 2014, 136, 10214-10217. 
28. Wu, F.; Song, Y.; Zhao, Z.; Zhang, S.; Yang, Z.; Li, Z.; Li, M.; Fan, Q.-H.; Liu, D., Preparation and Self-Assembly of Supramolecular Coil-Rod-Coil Triblock Copolymer PPO-dsDNA-PPO. Macromolecules 2015, 48, 7550-7556.

29. Alemdaroglu, F. E.; Safak, M.; Wang, J.; Berger, R.; Herrmann, A., DNA multiblock copolymers. Chem. Commun. 2007, 1358-1359.

30. Ayaz, M. S.; Kwak, M.; Alemdaroglu, F. E.; Wang, J.; Berger, R.; Herrmann, A., Synthesis of DNA block copolymers with extended nucleic acid segments by enzymatic ligation: cut and paste large hybrid architectures. Chem. Commun. 2011, 47, 2243-2245.

31. Safak, M.; Alemdaroglu, F. E.; Li, Y.; Ergen, E.; Herrmann, A., Polymerase Chain Reaction as an Efficient Tool for the Preparation of Block Copolymers. Adv. Mater. 2007, 19, 1499-1505.

32. Alemdaroglu, F. E.; Zhuang, W.; Zöphel, L.; Wang, J.; Berger, R.; Rabe, J. P.; Herrmann, A., Generation of Multiblock Copolymers by PCR: Synthesis, Visualization and Nanomechanical Properties. Nano Lett. 2009, 9, 3658-3662.

33. Edwardson, T. G. W.; Carneiro, K. M. M.; Serpell, C. J.; Sleiman, H. F., An Efficient and Modular Route to Sequence-Defined Polymers Appended to DNA. Angew. Chem., Int. Ed. 2014, 53, 4567-4571.

34. Serpell, C. J.; Edwardson, T. G. W.; Chidchob, P.; Carneiro, K. M. M.; Sleiman, H. F., Precision Polymers and 3D DNA Nanostructures: Emergent Assemblies from New Parameter Space. J. Am. Chem. Soc. 2014, 136, 15767-15774.

35. Appukutti, N.; Serpell, C. J., High definition polyphosphoesters: between nucleic acids and plastics. Polym. Chem. 2018, 9, 2210-2226.

36. Vybornyi, M.; Vyborna, Y.; Häner, R., DNA-inspired oligomers: from oligophosphates to functional materials. Chem. Soc. Rev. 2019, 48, 4347-4360.

37. For convenience, the term poly(phosphodiester)s and the corresponding acronym PPDE are used to denote the abiological segments. Nevertheless, nucleic acids are also poly(phosphodiester)s and therefore the whole DNA/PPDE bio-hybrid macromolecules are poly(phosphodiester)s, as underlined in the title of this article.

38. Al Ouahabi, A.; Charles, L.; Lutz, J.-F., Synthesis of Non-Natural Sequence-Encoded Polymers Using Phosphoramidite Chemistry. J. Am. Chem. Soc. 2015, 137, 5629-5635.

39. Mutlu, H.; Lutz, J.-F., Reading Polymers: Sequencing of Natural and Synthetic Macromolecules. Angew. Chem., Int. Ed. 2014, 53, 13010-13019.

40. Al Ouahabi, A.; Amalian, J.-A.; Charles, L.; Lutz, J.-F., Mass spectrometry sequencing of long digital polymers facilitated by programmed inter-byte fragmentation. Nat. Commun. 2017, 8, 967.

41. Cao, C.; Krapp, L. F.; Al Ouahabi, A.; König, N. F.; Cirauqui, N.; Radenovic, A.; Lutz, J.-F.; Peraro, M. D., Aerolysin nanopores decode digital information stored in tailored macromolecular analytes. Sci. $A d v$. 2020, 6, eabc2661. 
42. Kallenbach, N. R.; Ma, R.-I.; Seeman, N. C., An immobile nucleic acid junction constructed from oligonucleotides. Nature 1983, 305, 829-831.

43. Vitoc, C. I.; Mukerji, I., HU Binding to a DNA Four-Way Junction Probed by Förster Resonance Energy Transfer. Biochemistry 2011, 50, 1432-1441.

44. Szweda, R.; Tschopp, M.; Felix, O.; Decher, G.; Lutz, J.-F., Sequences of Sequences: Spatial Organization of Coded Matter through Layer-by-Layer Assembly of Digital Polymers. Angew. Chem., Int. Ed. 2018, 57, 15817-15821.

45. Lesnik, E. A.; Freier, S. M., Relative Thermodynamic Stability of DNA, RNA, and DNA:RNA Hybrid Duplexes: Relationship with Base Composition and Structure. Biochemistry 1995, 34, 10807-10815.

46. Owczarzy, R.; You, Y.; Moreira, B. G.; Manthey, J. A.; Huang, L.; Behlke, M. A.; Walder, J. A., Effects of Sodium Ions on DNA Duplex Oligomers: Improved Predictions of Melting Temperatures. Biochemistry 2004, 43, 3537-3554.

47. Hosono, N.; Gillissen, M. A. J.; Li, Y.; Sheiko, S. S.; Palmans, A. R. A.; Meijer, E. W., Orthogonal Self-Assembly in Folding Block Copolymers. J. Am. Chem. Soc. 2013, 135, 501-510.

48. Stals, P. J. M.; Li, Y.; Burdyńska, J.; Nicolaÿ, R.; Nese, A.; Palmans, A. R. A.; Meijer, E. W.; Matyjaszewski, K.; Sheiko, S. S., How Far Can We Push Polymer Architectures? J. Am. Chem. Soc. 2013, 135, 11421-11424.

49. Li, Y.; Tseng, Y. D.; Kwon, S. Y.; d'Espaux, L.; Bunch, J. S.; McEuen, P. L.; Luo, D., Controlled assembly of dendrimer-like DNA. Nat. Mater. 2004, 3, 38-42.

50. Mazur, A. K.; Maaloum, M., DNA flexibility on short length scales probed by atomic force microscopy. Phys. Rev. Lett. 2014, 112, 068104.

51. Duckett, D. R.; Murchie, A. I. H.; Diekmann, S.; von Kitzing, E.; Kemper, B.; Lilley, D. M. J., The structure of the holliday junction, and its resolution. Cell 1988, 55, 79-89.

52. Wang, W.; Nocka, L. M.; Wiemann, B. Z.; Hinckley, D. M.; Mukerji, I.; Starr, F. W., Holliday Junction Thermodynamics and Structure: Coarse-Grained Simulations and Experiments. Sci. Rep. 2016, 6, 22863.

53. Steinkoenig, J.; Aksakal, R.; Du Prez, F., Molecular access to multi-dimensionally encoded information. Eur. Polym. J. 2019, 120, 109260.

54. König, N. F.; Al Ouahabi, A.; Oswald, L.; Szweda, R.; Charles, L.; Lutz, J.-F., Photoeditable macromolecular information. Nat. Commun. 2019, 10, 3774. 